\title{
«El inmortal» de Jorge Luis Borges: el yo, infinitos, absolutos y vocabularios finales
}

\section{Jorge Luis Borges's «The Immortal»: the Self, Infinites, Absolutes, and Final Vocabularies}

Jorge Sagastume

Dickinson College, Pensilvania

sagastuj@dickinson.edu

Resumen - Una obra frecuentemente consultada por Jorge Luis Borges fue Matemáticas e imaginación, de E. Kasner y J. Newman, en la que se discute la teoría de los conjuntos (que es la rama de la matemática que estudia la relación entre conjuntos), propuesta por Georg Cantor (1845-1918), y mediante la cual se crea la aritmética transfinita (que va más allá de la finita) y se establece un sistema epistémico para representar los diversos niveles del infinito. Así, Cantor le asigna a esas infinitudes la primera letra del alfabeto hebreo, el Aleph, seguido de un determinado número, dependiendo del nivel de infinitud (Aleph-cero, Aleph-uno, etc.). Borges, de esa manera, teje varias de sus narraciones en las que se trata el tema del infinito y del absoluto: un ejemplo de ello es la colección de relatos bajo el título El Aleph, que abre con el cuento «El inmortal» y cierra con el que le da el título a la colección. El presente ensayo tiene el propósito de estudiar «El inmortal» bajo la óptica cantoriana, para hablar de un absoluto en particular: el yo, y sugerir que no es posible establecer un vocabulario final o una definición definitiva sobre el tema en cuestión. Tal imposibilidad, propone Borges, está dada en parte por la finitud lingüística, mientras que por otro lado la falibilidad de la memoria juega también un papel crucial en todo intento de definición. Sin embargo, como buen ironista, el autor a través de «El inmortal» es capaz de proveer una redescripción del tema mediante un lenguaje transfinito, sin pretender establecer un vocabulario final sobre la materia, sino, al contrario, tratando de resolver ciertas paradojas a las vez que revela otras, promoviendo así el permanente diálogo entre las distintas disciplinas. Aunque el ensayo se enfoca en el análisis de «El inmortal», a fin de desarrollar el problema propuesto, también estudia otros relatos contenidos en $\mathrm{El}$ Aleph, y utiliza un acercamiento teórico que se enmarca en la filosofía de la lengua.

Palabras clave: Borges, inmortal, Aleph, Cantor, identidad.

Abstract • Jorge Luis Borges often consulted Mathematics and Imagination by E. Kasner and J. Newman, where they address the set theory (branch of mathematics that studies the relationship between sets) proposed by Georg Cantor (18451918), and in which transfinite arithmetic (beyond finite arithmetic) is established, and an epistemic system created to represent different levels of the infinite. Thus, Cantor labels the different levels of the infinite by assigning to each the first let- 
ter of the Hebrew alphabet, the Aleph, followed by a number, depending on the level of infinite he is referring to (Aleph-zero, Aleph-one, etc.). Following these ideas, Borges weaves several narratives, discussing the infinite and the absolute. An example of such narratives is the collection of stories compiled under the title The Aleph, which opens with "The Immortal» and closes with the story that gives the collection its title. The objective of this paper is to study «The Immortal» under the Cantorian lens, so as to discuss one particular absolute, the self, and to suggest that it is impossible to establish a final vocabulary, or a definite definition, about this topic. This impossibility, Borges proposes, is in part due to the apparent finitude of language, on the one hand, and on the other, the fallible attributes of human memory are also crucial when it comes to defining anything. However, being the ironist Borges is, he is capable of providing through «The Immortal» a re-description of these issues by means of a transfinite language that resolves some paradoxes while at the same time reveals others. Due to this way of writing, I propose Borges fosters a continuation of the dialogue among different disciplines. Though I will center my analysis on «The Immortal», to develop these ideas I will also revisit other stories in The Aleph departing from a theoretical approach rooted in the philosophy of language.

Keywords: Borges, Immortal, Aleph, Cantor, Identity.

Jorge Luis Borges abre el cuento «El libro de arena» con las siguientes palabras: «La línea consta de un número infinito de puntos; el plano, de un número infinito de líneas; el volumen de un número infinito de planos; el hipervolumen, de un número infinito de hipervolúmenes [...]» (Obras completas III, 68), para luego desarrollar el relato, cuyo tema central, podríamos decir, es el del conjunto infinito de fuentes de conocimiento disponibles a través de un infinito número de escrituras, todas compendiadas en un solo volumen que no tiene comienzo ni fin, sugiriéndose que a pesar de que las fuentes puedan ser infinitas, el conocimiento en sí quizá sea limitado. El infinito y el absoluto son temas recurrentes a lo largo de la obra del autor. Basta repasar muy rápidamente sus escritos para darnos cuenta de que esos temas, generalmente basados en principios matemáticos, se manifiestan casi como una obsesión ${ }^{1}$. Su interés en ellos, creemos, no reside en el hecho de que puedan o no ser verificables; nos parece percibir que Borges no creía en arquetipos eternos, sino que los utilizaba porque de una u otra manera le permitían proponer que nada es real, ni siquiera el lenguaje matemático que, por lo general, es considerado un lenguaje exacto.

Otro tema conexo es el de los catálogos, que aparece incesantemente en la obra borgesiana. Lo vemos en «La biblioteca de Babel», por ejemplo, en la forma de una búsqueda

\footnotetext{
Sin pensar con mucho esfuerzo, se nos ocurren varios escritos de Borges en los que las bases de los argumentos presentados tienen sus orígenes en la matemática y su relación con el infinito y la búsqueda de un absoluto: «El disco», «El libro de arena», «La biblioteca de Babel», «La lotería de Babilonia», «Del rigor de la ciencia», «Examen de la obra de Herbert Quain», "Argumentum ornithologicum», «La perpetua carrera de Aquiles y la tortuga», "Avatares de la tortuga», «El idioma analítico de John Wilkins», «La doctrina de los ciclos», «Pascal», «La esfera de Pascal», "Ruinas circulares», «El inmortal», "La muerte y la brújula», «El Aleph» y la lista podría continuar.
} 
de un catálogo que contenga todos los catálogos. Pero no se trata de una simple lista que contenga todos los títulos habidos y por haber que pueden considerarse fuentes de conocimiento, sino que se trata de una relación ordenada de títulos que están relacionados entre sí. En otras palabras, se trata de un conjunto absoluto que contenga absolutamente todos los conjuntos de las fuentes de conocimiento y que descubra a la vez la relación entre ellos. Pero dentro de ese conjunto absoluto tenemos conjuntos y subconjuntos, por ejemplo los conjuntos de libros de literatura, de filosofía, de historia, de ciencias, etc., que a su vez también están compuestos de subconjuntos. Tomemos como ejemplo el de los libros de literatura, dentro del cual tenemos el subconjunto que comprende todos los libros de poesía, el de los libros de prosa, el de los libros de drama, etc. Así, cada uno de esos subconjuntos es en sí un conjunto individual, pero determinar el número de elementos o el catálogo (la cardinalidad del conjunto, en términos matemáticos) resulta imposible si partimos de una aritmética finita, es decir la aritmética que gobierna nuestro diario vivir. Ir más allá de esa aritmética finita sería considerado impráctico y metafísico. Pero para Borges, no por ser metafísicos no han de considerarse; para él, como mencionamos antes, en realidad todo es metafísico o, como le gustaba rotularlo, fantástico. Hablar de cualquier cosa, real o imaginaria, describir, definir, identificar, al fin y al cabo "es incurrir en tautologías» (Obras completas I, 470). El lenguaje con el que contamos (incluso el matemático) nos limita, nos encajona en un universo finito.

De allí que Borges se sintiera atraído por personajes que intentaran ir más allá de esta finitud, y un libro que consultaba con frecuencia es Matemáticas e imaginación, de E. Kasner y J. Newman, en el que se discute la teoría de los conjuntos (que es la rama de la matemática que estudia la relación entre conjuntos), propuesta por Georg Cantor (18451918), y mediante la cual crea la aritmética transfinita (que va más allá de la finita) y establece un sistema epistémico nuevo para representar los diversos niveles del infinito. Así, Cantor le asigna a esas infinitudes la primera letra del alfabeto hebreo, el Aleph, seguido de un determinado número, dependiendo del nivel de infinitud (Aleph-cero, Aleph-uno, etc.). Obviaremos aquí el análisis matemático y las infinitas operaciones posibles mediante este nuevo sistema, porque no vienen al caso. Nuestro interés en mencionar tal sistema está en que, sospechamos, es la idea detrás de las ideas borgesianas de los catálogos y la que dio lugar a la publicación de la colección de relatos bajo el título El Aleph en 1949²; de hecho, hacia el final del cuento homónimo, Borges incluso menciona específicamente la aritmética transfinita (Obras completas I, 627).

En El Aleph, cada uno de los cuentos, de una u otra manera, trata sobre algún catálogo (o conjunto) en particular ${ }^{3}$, para llegar a la conclusión de que no nos es posible establecer un vocabulario final sobre el tema que se discute, aunque no por eso debemos

\footnotetext{
Sobre la conexión entre Borges y Cantor en el cuento «El Aleph», véase el interesante ensayo de Juan Antonio Hernández, titulado "Biografía del infinito: La noción de transfinitud en Georg Cantor y su presencia en la prosa de Jorge Luis Borges».

3 Así, para dar algunos ejemplo, vemos en «Los teólogos», entre otras cosas, el tema del tiempo y de un universo fuera del tiempo, partiendo de una perspectiva finita y tratando de ir más allá de la misma para intentar establecer una definición definitiva del tiempo; "Historia del guerrero y la cautiva», "Biografía de Tadeo Isidoro Cruz» y «Emma Zunz» discuten la idea de un conjunto absoluto que comprendería los diferentes destinos del ser humano, para concluir que el destino de un hombre es el de todos los hombres (tema típicamente cantoriano en el que se demuestra que cada parte de todo conjunto se puede poner en correspondencia directa, uno a uno, con cada uno de sus elementos); «La escritura del Dios» trata sobre un lenguaje divino, absoluto, en el que la correspondencia entre significado y significante no tiene relevancia, puesto que no consta de un lenguaje finito.
} 
dejar de lado la constante redescripción de ellos ${ }^{4}$. El relato que cierra la colección es el que le da el título a la misma. Ese Aleph que el personaje Borges ve en el sótano de la casa de Daneri es un conjunto supremo y absoluto que abarca el Todo: lo pasado, lo presente y lo por venir, además de permitirle al espectador Borges dilucidar todos los secretos del universo, resolviendo así toda aporía y explicando toda paradoja ${ }^{5}$. Ese orificio, esa «esfera cuyo centro está en todas partes y la circunferencia en ninguna» (Obras completas I, 625) y que adquiere la forma de un hexágono en «La biblioteca de Babel» vendría a ser el conjunto de todos los conjuntos que componen el infinito universo.

El cuento «El Aleph» es, entonces, el que resume la idea general de la colección de relatos: no es posible llegar a definir nada de manera absoluta, pero es necesario volver sobre ciertos temas mediante permanentes redescripciones de los mismos. La razón fundamental de esa imposibilidad queda sugerida a lo largo de la obra de Borges, pero de manera específica es mencionada en ese cuento, cuando el narrador reflexiona sobre lo que ha visto y declara: «Lo que vieron mis ojos fue simultáneo; lo que transcribiré, sucesivo, porque el lenguaje lo es. Algo, sin embargo, recogeré» (Obras completas I, 625). El lenguaje, puesto que es diacrónico, impide la definición absoluta del universo o de cualquier elemento del mismo, incluso el más simple, puesto que todo elemento o evento en sí se presenta como fenómeno sincrónico. Pero ese «algo, sin embargo, recogeré» se convierte en la esencia de la escritura borgesiana, que consta de las características típicas de un ironista, que acepta las limitaciones lingüísticas y sabe que la única posibilidad es la de continuar proveyendo redescripciones que nos fuercen a considerar los mismos temas bajo diferentes lentes, aun cuando las materias a tratarse vayan más allá de nuestra visión finita de la realidad y nos lleven a considerar lo generalmente visto como metafísico ${ }^{6}$.

Pero el propósito del presente ensayo no es el de analizar todos los relatos que componen la colección El Aleph; ese es tema para un libro. Su tarea es la de estudiar, bajo la óptica discutida hasta el momento, el cuento titulado «El inmortal», que abre la colección y que trata sobre el intento infructuoso de definición de uno de los conjuntos que componen la realidad; en este caso, según nuestra lectura, se trata de la definición de la identi$\mathrm{dad}^{7}$. No obstante, a lo largo del ensayo, a fin de corroborar lo propuesto, repasaremos

4 Utilizamos la expresión «vocabulario final» siguiendo el modelo de Richard Rorty, quien creó la terminología al referirse a la fútil búsqueda de las distintas disciplinas de hallar una descripción final o definitiva de los distintos elementos que componen nuestra realidad.

5 Como nota de aclaración, el término "universo" se utiliza en el presente trabajo a la manera borgesiana y que se ajusta a la definición del diccionario: «conjunto de todas las cosas creadas», que también coincide con la definición de la palabra «cosmos»(RAE). Este conjunto de todas las cosas creadas incluye, por supuesto, al ser humano.

6 No utilizamos aquí el término ironista de la manera tradicional, sino al estilo de Richard Rorty. En primer lugar, según el autor el ironista mantiene «radical and continuing doubts about the final vocabulary she currently uses, because she has been impressed by other vocabularies [...]». En segundo lugar, "she realizes that argument phrased in her present vocabulary can neither underwrite nor dissolve these doubts [...]». En tercer lugar, «insofar as she philosophizes about her situation, she does not think her final vocabulary is closer to reality than others, that it is in touch with a power not herself». Y, por último, "Ironists who are inclined to philosophize see the choice between vocabularies as made neither within a neutral and universal metavocabulary nor by an attempt to fight one's way past appearances to the real, but simply by playing the new off against the old» (73).

«El inmortal», por supuesto, permite otras lecturas sobre este mismo tema. Por ejemplo, Abraham Mansbach sugiere que Borges llega a la misma conclusión que Heidegger, y que es la muerte la única posibilidad del ser de convertirse en un individuo único y diferente a todos los demás; la individualidad, nos dice Mansbach, reside en saberse finito, es decir mortal. 
algunos otros relatos contenidos en la colección, así como también otros cuentos fuera de El Aleph que nos ayudarán a discutir con mayor claridad la idea que aquí se propone.

A primera vista, el lector de «El inmortal» se ve forzado a descubrir la obvia característica circular de la literatura. De allí que algunos críticos consideren el cuento como un laberinto intertextual ${ }^{8}$. Ese laberinto que siempre conecta conceptos, obras e ideas aparentemente ajenas, entre otras cosas es un comentario que va más allá del tema de la literatura. Dada la característica caótica de la narrativa que el cuento presenta, podríamos decir que la primera reacción del lector concienzudo será la de darle sentido a las palabras. Naturalmente, el sentido comienza a vislumbrarse cuando el lector cree identificar ciertas enunciaciones y el sujeto de las mismas o el sujeto de los diferentes enunciados. Pero el problema con «El inmortal» está en que es imposible saber con exactitud quién dice o hace esto o aquello. No podemos determinar claramente quiénes son Joseph Cartaphilus, Marco Flaminio Rufo, el troglodita Argos, Homero y los demás personajes que pueblan las páginas del relato. Es cierto que Borges estratégicamente incluye ciertos códigos identificadores con la falaz intención de ayudar al lector a establecer una conexión entre los enunciados, enunciaciones y los sujetos de los mismos, pero, en realidad, cuando el lector cree haber logrado identificar quién habla o actúa, todo indicio de identidad se desvanece, llevándolo una vez más a la decepción. Es como si el lector tuviera que infructuosamente tratar de identificar precisamente el significado de un significante. Sólo podemos decir que algún sujeto dice o hace esto o aquello en la narración, pero no podemos establecer definitivamente quién es el autor de la acción; el sujeto siempre se escurre. Y en parte se escurre a causa de la falibilidad del lenguaje; en parte a causa de la falibilidad de la memoria del narrador. El relato se convierte así en un juego de ideas articuladas en diversos vocabularios que nos lleva a reflexionar, como se ha propuesto, sobre la imposibilidad de alcanzar un vocabulario final que pueda establecerse como normativo a la hora de definir el $y o^{9}$.

Toda definición, por supuesto, involucra inevitablemente el lenguaje, el cual, como bien lo sabemos después de Ludwig Wittgenstein y de los románticos alemanes, se desarrolla a partir de permanentes contingencias ${ }^{10}$, es decir, no es en sí un elemento estable, sino que evoluciona a medida que diferentes situaciones crean la necesidad de redefinir viejos términos o de crear otros nuevos. Eso es algo de lo que Borges estaba bien enterado y, de hecho, es el tema de varios de sus relatos ${ }^{11}$. Así como el lenguaje está siempre supeditado a contingencias, el ser humano también lo está, puesto que se halla inseparablemente unido al lenguaje y, por consiguiente, su yo tampoco es una entidad estable. Si recordamos otro de los relatos que forman parte de El Aleph, «La escritura del Dios», veremos que el narrador señala que «Un hombre se confunde, gradualmente, con la forma de su destino; un hombre es, a la larga, sus circunstancias» (Obras completas I, 598). La preocupación borgesiana por el concepto de identidad data de 1922, cuando publica

Véase, por ejemplo, Christ.

9 Borges, a lo largo de su obra, utiliza indistintamente los términos «identidad», «personalidad» y «ser» para referirse al «yo». A fin de mantener una consistencia y evitar confusión, en el presente ensayo seguiremos la fórmula borgesiana, a menos que se quiera señalar algo diferente, en cuyo caso así será indicado.

10 Utilizaremos a lo largo del ensayo el término "contingencia» sin ajustarnos precisamente a la definición enciclopédica del mismo, sino entendiéndolo como Ludwig Wittgenstein, Richard Rorty, Donald Davidson y otros filósofos de la lengua, quienes lo usan para referirse a todo evento que modifica el lenguaje y al ser. Este término, podríamos decir, es privativo del campo de la filosofía de la lengua.

11 Para la la conexión entre Borges y Wittgenstein, véase Mualem. 
su primer libro bajo el título Inquisiciones, que incluye el ensayo «La nadería de la personalidad», en el que, al referirse al yo, le dice al lector: "sólo soy una certidumbre que inquiere las palabras más aptas para persuadir tu atención. Ese propósito y algunas sensaciones musculares y la visión de límpida enramada que ponen frente a mi ventana los árboles, constituyen mi yo actual» (Inquisiciones, 94). Su yo, entonces, como podemos observar, depende del momento y de ciertas contingencias, mientras que su definición depende directamente del lenguaje y de las intenciones de aquel al que le toca definir su yo.

En el cuento «El inmortal» estas ideas se ven con mayor claridad incluso, pero antes de desarrollar ese tema revisemos otro que también interfiere en la definición absoluta del yo. Nos referimos a la memoria, que también se discute en «El inmortal», pero que viene tratándose en Borges desde los inicios de su carrera literaria. En «La nadería de la personalidad» leemos que:

No hay tal yo de conjunto. Equivócase quien define la identidad personal como la posesión privativa de algún erario de recuerdos. Quien tal afirma, abusa del símbolo que plasma la memoria en figura de duradera y palpable troj o almacén, cuando no es sino el nombre mediante el cual indicamos que entre la innumerabilidad de todos los estados de conciencia, muchos acontecen de nuevo en forma borrosa. Además, si arraiga la personalidad en el recuerdo, ¿a qué tenencia pretender sobre los instantes cumplidos que, por cotidianos o añejos, no estamparon en nosotros una grabazón perdurable? Apilados en años, yacen inaccesibles a nuestra anhelante codicia (Inquisiciones, 94-5).

No sólo la memoria es falible y, por lo tanto, hace imposible que el ser recuerde absolutamente todas las contingencias a las que se ha enfrentado a lo largo de su vida y que han forjado su yo, sino que ese ‘yo de conjunto〉, es decir ese yo innato, no existe, ya que cambia permanentemente.

En «El inmortal» tenemos un personaje que no muere, que se enfrenta a un sinnúmero de contingencias y cuyo destino se entremezcla con el destino de un número infinito de destinos de otros individuos; un personaje que, además, es capaz de hablar todas las lenguas y que ha leído todos los libros habidos y por haber. Sin embargo, su memoria es falible y, por lo tanto, no es capaz de recordar todas sus contingencias de manera absoluta; su posición de individuo inmortal, entonces, no lo aventaja en nada, sino que lo ubica en el lugar de cualquier otro hombre, llegando a la conclusión de que su destino es el mismo que el de todo ser humano; el ser un hombre equivale a ser todos los hombres y en sí nadie (Obras completas I, 544).

En las páginas que siguen, entonces, analizaremos el relato partiendo de esas premisas. Nos referiremos al tema del lenguaje y a cómo éste no sólo influye en el desarrollo de todo yo, sino que también limita al ser a la hora de intentar establecer una definición de sí mismo o un vocabulario final, un conjunto absoluto, sobre lo que significa ser. También estudiaremos el tema de la memoria y el de sus infinitas ramificaciones, para finalmente sugerir que «El inmortal» es una invaluable pieza literaria ironista que nos lleva a considerar una cuestión sumamente antigua e indefinible bajo una lente que no quiere ser definitiva, que no pretende resolver ninguna aporía, sino abrir un sinnúmero de nuevas aporías que nos permiten mantener continuamente el diálogo entre las diversas disciplinas del conocimiento a través de la metáfora, que, para Borges, no difiere de otras formas lingüísticas. Ya en 1921 escribía que «No existe una esencial desemejanza entre la metáfora y lo que los profesionales de la ciencia nombran la explicación de un fenómeno. Ambas son una vinculación tramada entre dos cosas distintas, a una de las cuales se la 
trasiega en la otra. Ambas son igualmente verdaderas o falsas» (Textos recobrados, 114). Como Donald Davidson, Borges creía también que el gran valor del lenguaje metafórico está en el hecho de que la metáfora contiene todas las posibles explicaciones que de ella se puedan sugerir, pero ninguna explicación en particular es suficiente para explicarla definitivamente (Davidson, 247). Partiendo de tales ideas sospechamos también que para Borges el lenguaje no es un medio entre el ser y la realidad, sino que es en sí una entidad independiente, con leyes propias, a través de las cuales podemos decir que ciertos dictámenes son verdaderos o falsos.

A lo largo de «El inmortal» existen reiteradas menciones del tema de la lengua con un propósito desmitificador, por ejemplo cuando el supuesto narrador describe su encuentro con los trogloditas, quienes, se descubre luego, son los inmortales. Ellos, señala el texto, "carecen del comercio de la palabra» (Obras completas I, 534). Los inmortales, en su frustrada búsqueda de un lenguaje en el que el significante coincidiera con el significado a fin de establecer un vocabulario final sobre la realidad, se entregaron al silencio, a la contemplación, al pensamiento (541). Sin embargo, uno de ellos, aunque no pronuncia palabra alguna hasta mucho después, continúa intentando hallar ese lenguaje ideal que le permita explicar la realidad. Nos referimos a Argos, u Homero, quien sigue al narrador del cuento hasta la región de los sótanos y al salir del último de ellos se lo encuentra afuera, aguardándolo,

tirado en la arena, donde trazaba torpemente y borraba una hilera de signos, que eran como las letras de los sueños que uno está a punto de entender y luego se juntan. Al principio, creí que se trataba de una escritura bárbara; después vi qué absurdo imaginar que hombres que no llegaron a la palabra lleguen a la escritura. Además, ninguna de las formas era igual a otra, lo cual excluía o alejaba la posibilidad de que fueran simbólicas. El hombre las trazaba, las miraba y las corregía. De golpe, como si le fastidiara ese juego, las borró con la palma y el antebrazo (538).

El narrador, que hasta ese momento no sabía quién era el troglodita, no se percata de lo que Argos realmente está tratando de hacer. Es más, el protagonista hasta llega a conjeturar que el troglodita no percibe de la misma manera que él los sonidos de las palabras que procuraba inculcarle, pero llega a la conclusión de que sería imposible que no entendiera las palabras en sí. Pensó que quizá, como los monos de los etíopes, optaba por callarse para que no se le asignara una labor (539), atribuyéndole al silencio de Argos el valor de la suspicacia o temor. Pero, la tarea que mantenía ocupado a Argos era la de intentar producir signos epistémicos capaces de convertirse en un medio entre el ser y la realidad, para que el lenguaje dejara de ser una mera metáfora o simulacro de ella. El narrador, no obstante, es consciente de que tal cosa es imposible; sabe que «Fácilmente aceptamos la realidad, acaso porque intuimos que nada es real» (539-40). Argos, u Homero, también lo sospecha, pero no se da por vencido, aunque admite que toda la descripción de la realidad es una invención lingüística. Cuando el narrador le pregunta qué sabe sobre $L a$ Odisea, el troglodita le responde que «ya habrán pasado mil cien años desde que la invent[ó]» (540).

El tema del lenguaje, sin embargo, se menciona de manera más específica en el prólogo del supuesto traductor del manuscrito que había sido hallado en uno de los volúmenes de La Ilíada traducida por Pope. La traducción de dicho manuscrito, que es en sí el cuento, pretende ser una versión en español del texto en inglés. El prólogo concluye con las siguientes palabras: «El original está redactado en inglés y abunda en latinismos. La 
versión que ofrecemos es literal» (533). De por sí es una declaración muy ambigua. Si reescribiésemos estas dos oraciones, a fin de aclarar su significado, con la ayuda de un diccionario y ajustándonos a la definición literal de cada una de las palabras, podríamos conjeturar que lo que el traductor quiso decir fue lo siguiente: la obra producida directamente por su autor, sin ser copia, imitación o traducción de otra, pone por escrito, en inglés, lo que sucedió, se acordó o pensó con anterioridad; incluye muchos giros o modos de hablar propios y privativos de la lengua latina. La traducción o interpretación que ofrecemos, es decir la manera en que tenemos de referirnos a lo expuesto en el original, es conforme a la letra del texto, o al sentido exacto y propio, y no lato ni figurado de las palabras empleadas en él. Ello, por supuesto, presupondría una traducción perfecta y total del manuscrito del inglés al español. Por medio del mismo prólogo también sabemos que Joseph Cartaphilus, «Se manejaba con fluidez e ignorancia en diversas lenguas; en muy pocos minutos pasó del francés al inglés y del inglés a una conjunción enigmática de español de Salónica y de portugués de Macao» (533). Todo parece subrayar el tema de la traducción y la habilidad del personaje de dominar todas las lenguas con completa soltura. En otras palabras, parece poder ir más allá de toda posible barrera lingüística y cultural ${ }^{12}$. Pero aun si fuese posible para Cartaphilus trascender esas barreras, ya que habla todas las lenguas y ha vivido todas las culturas porque ha vivido durante siglos, la imposibilidad de realizar una traducción total todavía tiene vigencia, puesto que el lenguaje que utilizamos es tan sólo una metáfora y los signos característicos del mismo, sus significantes, no corresponden con sus significados. De manera que vemos que esa condición de ser inmortal de nada le sirve a la hora de definir algo; como dijimos antes, él se halla en la posición de cualquier mortal.

Y así, la preocupación sobre el lenguaje poco a poco se hace más sugestiva en «El inmortal», yendo desde el tema de la traducción, de la habilidad de trascender las barreras lingüísticas y culturales, hasta tocar el aspecto de su influencia en el desarrollo del individuo y la inhabilidad del la lengua de servir fehacientemente como intermediario entre el ser y el universo que lo rodea. Cuanto más conoce el narrador a Argos más enigmática se torna la relación entre ellos, hasta que el primero llega a formular la siguiente conjetura:

Pensé que Argos y yo participábamos de universos distintos; pensé que nuestras percepciones eran iguales, pero que Argos las combinaba de otra manera [...] Pensé en un mundo sin memoria, sin tiempo; consideré la posibilidad de un lenguaje que ignorara los sustantivos, un lenguaje de verbos impersonales o de indeclinables epítetos (539).

Si tenemos en cuenta las habilidades lingüísticas de Cartaphilus y la conjetura que acabamos de citar, parecería que en realidad el narrador estuviera considerando la posibilidad de un lenguaje ideal, absoluto o total. Pero nos parece percibir que en realidad Borges está precisamente cuestionando la idea misma de una estructura universal, permitiendo así la especulación sobre la relación que existe entre el lenguaje y nuestro entendimiento del mundo; en el caso particular de «El inmortal», la relación entre el lenguaje y nuestro entendimiento del yo.

Volviendo a la cita anterior, incluso sería posible pensar que Borges estuviese considerando la posibilidad de un entendimiento prelingüístico, o sea un entendimiento de-

Jon Stewart usa el cuento borgesiano «La busca de Averröes» para demostrar que «cultural distances [...] can on occasion constitute spaces which no degree of imagination, technology, or erudition can ever help us traverse». 
terminado por los estímulos sensoriales que dan lugar a nuestras percepciones, al estilo de Platón. Pero si el autor creyera que podemos adquirir conocimiento independientemente de los conceptos, un conocimiento prelingüístico, o conocimiento sin la mediación lingüística, entonces tal vez deberíamos buscar ese lenguaje ideal. Sin embargo, su idea, creemos, es la opuesta: no existe tal necesidad. Es más, Borges niega la idea del entendimiento prelingüístico, reconociendo que nuestra identidad, y específicamente la identidad del narrador, toma forma a partir del aparato conceptual que hereda. El autor, a nuestro modo de ver, está identificando el hecho de que nosotros, como usuarios del lenguaje, continuamente somos partícipes de un juego lingüístico que evoluciona sin cesar a través de las contingencias a las que se enfrenta ${ }^{13}$. Esta idea no es exclusiva de «El inmortal», sino que es una preocupación que se presenta con frecuencia en la obra borgesiana. Consideremos, como ejemplo adicional, el cuento «Tlön, Uqbar, Orbis Tertius», donde el narrador señala que: «Entonces desaparecerán del planeta el inglés y el mero español. El mundo será Tlön. Yo no hago caso, yo sigo revisando en los quietos días del hotel de Adrogué una indecisa traducción quevediana (que no pienso dar a la imprenta) del Urn Burial de Browne» (Obras completas I, 443).

Podemos inferir, entonces, que es probable que Borges sea de la opinión de que el juego lingüístico en el que participamos como usuarios de un lenguaje podría llegar a convertirse en obsoleto, o que podría ser reemplazado en su totalidad por otro, y que para que ello no ocurra debemos adaptarnos permanentemente al juego lingüístico del momento. De esa manera reconocemos el valor metafórico de todo sistema lingüístico y lo vemos como una útil herramienta que nos permite constantemente formular redescripciones de la realidad, sin la necesidad de establecer un vocabulario final que sí causaría la cesación de la lengua.

«El inmortal», entonces, sugiere que como seres humanos no deberíamos tratar de hallar un sistema epistémico absoluto que nos permitiera entender la esencia de nuestra identidad, puesto que tal tarea resultaría imposible, sino que tan sólo deberíamos reconocer la deuda que tenemos con nuestros precursores ${ }^{14}$. De hecho, el narrador del relato señala que "[Homero] fue como un dios que creara el cosmos y luego el caos» (540). Es decir, crea un cierto aparato conceptual literario que determina el orden y también el desorden, o el caos, que heredamos ${ }^{15}$. Dicho de otra forma, él hace posible la idea de que los seres humanos compartan el uno con el otro las experiencias que los identifican mediante la perpetuación de un juego lingüístico que provee un marco apropiado para comparar y contrastar esas experiencias pero, a la vez, dando lugar a que sus descendientes se enfrenten al mundo en el que les toque vivir con las herramientas que ellos mismos hayan creado. No obstante, como ironista, Borges también sugiere, a través del cuento

Utilizamos aquí la expresión «juego lingüístico» en el sentido lyotardiano (Lyotard).

14 Utilizamos el término "precursor» de la misma manera que Harold Bloom lo usa. Por ejemplo, en The Anxiety of Influence: A Theory of Poetry, el autor menciona: «For every poet begins (though <unconsciously») by rebelling more strongly against the consciousness of death's necessity than all other men and women do. The young citizen of poetry, or ephebe as Athens would have called him, is already the anti-natural or antithetical man, and from his start as a poet he quests for an impossible object, as his precursor quested before him» (10).

15 Borges mismo, en una entrevista con Osvaldo Ferrari, subraya el tema: «sin duda Homero tenía su Homero. Ya que la literatura siempre presupone un maestro, o una tradición» (Ferrari, 30). Ello sugiere que aunque no tengamos registros literarios que atestigüen la existencia de la tragedia previo a Homero, y que quizá hayan influido en él, la posibilidad existe. Homero es, en un sentido, el punto de partida, el conocimiento a priori del cual partimos. 
en sí, que deberíamos permitirnos ver la realidad más allá de la finitud del lenguaje, puesto que el no hacerlo aniquila la imaginación, que es precisamente lo que permite la redescripción de la realidad dentro de un ámbito que podría llamarse metafísico, pero que sólo es metafísico si se lo ve desde el punto de vista finito de las ciencias empíricas. Como dijimos antes, para el autor no existe diferencia entre las ciencias y la literatura, ambas son metáforas que pueden ser verdaderas o falsas.

Ahora bien, como si el tema del lenguaje y su influencia en el yo no fueran ya evidentes, el narrador de «El inmortal» vuelve a hacer hincapié en ello una y otra vez a lo largo del cuento, pero en especial hacia el final; al reflexionar sobre lo vivido en las previas centurias señala: "Yo he sido Homero; en breve, seré Nadie, como Ulises; en breve seré todos: estaré muerto» $(544)^{16}$. De esa reflexión del narrador podemos deducir, por lo menos, tres comentarios. Por un lado, si recordamos ese pasaje en La Odisea, también recordaremos la inhabilidad de los cíclopes de entender el comentario con doble sentido sobre el falso nombre de Odiseo, o sea Nadie. Odiseo los engaña usando un lenguaje no referencial: al llamarse a sí mismo Nadie, uno de los cíclopes grita pidiendo auxilio y declara ¡Nadie me está matando! Como los demás cíclopes tampoco entienden el lenguaje utilizado en forma no referencial, no llegan a darse cuenta del peligro que Nadie, es decir Odiseo, es decir Ulises, representa. Ellos asumen que existe una correspondencia entre el signo lingüístico y su referente ${ }^{17}$. El segundo comentario que se desprende de la cita nos refiere al hecho de que el narrador de «El inmortal» ha pensado en Odiseo porque implica también una decisión final, o una resignación a una condición determinada, la muerte, y la imposibilidad de hallar o crear un lenguaje absoluto. El tercer comentario, y quizá el más agudo, nos lleva a pensar en las teorías cantorianas de los conjuntos que, creemos, Borges conocía muy bien a través de Matemáticas e imaginación, donde los autores definen el conjunto infinito cantoriano de la siguiente manera: «Un conjunto infinito es aquel conjunto que puede ponerse en correspondencia recíproca, uno a uno, con un subconjunto propio de sí mismo» (E. Kasner y J. Newman, 56). Es decir, cada elemento del subconjunto puede ponerse en correspondencia directa, elemento por elemento, con los elementos del conjunto al que pertenece. Siguiendo esa teoría, entonces, es fácil deducir con Borges que un hombre, consiguientemente, es todos los hombres ${ }^{18}$. El destino de un hombre en particular es el destino de todos los hombres y viceversa. En su relato titulado «El tiempo circular», el autor esclarece aún más esta idea:

Si los destinos de Edgar Allan Poe, de los vikingos, de Judas Iscariote y de mi lector secretamente son el mismo destino - el único destino posible-, la historia universal es la de un solo hombre. En rigor, Marco Aurelio no nos impone esta simplificación enigmática [...] Marco Aurelio afirma la analogía, no la identidad, de los muchos destinos individuales. Afirma que cualquier lapso - un siglo, un año, una sola noche, tal vez el inasible presente- contiene íntegramente la historia (Obras completas I, 385)

16 Notemos, además, que utiliza la forma latina y no la helénica para referirse a Odiseo, enfatizando aún más el tema del juego lingüístico.

17 Reynaldo Riva, en su ensayo «Mélanges: Asedios a 〈El inmortal»», es el único crítico que ha identificado este episodio de La Odisea en «El inmortal», pero sin identificar ni el juego lingǘrtico de Homero ni el de Borges.

18 Otra interpretación es posible, por supuesto. Riva, por ejemplo, sugiere que Borges hace esta afirmación partiendo de la doctrina panteísta (320). 
Debemos concluir, entonces, que si un momento en la inmensidad de la historia humana contiene toda la historia, el narrador inmortal, por su larga existencia, y a diferencia de un ser mortal destinado a vivir quizá a lo sumo una centuria, es capaz de analizar el fenómeno a través de su múltiple contacto con múltiples analogías de destinos individuales. Pero al fin y al cabo, no le hacía falta vivir sin la capacidad de morir, puesto que su condición es la misma que la de cualquier ser mortal. Por otro lado, regresando a la idea de Odiseo y Nadie, vemos con claridad ahora que la decisión del narrador del cuento de buscar una vez más el río que devolviera la mortalidad es lógica, puesto que reconoce su condición y la única decisión viable es la de volver a ser como todos los hombres, Nadie, o sin identidad única e inamovible y recurrir a la redescripción a través de la metáfora sin intentar alcanzar un vocabulario final.

Como se sugirió al inicio, otro tema ligado al lenguaje a la hora de definir el yo es el de la memoria, conexión explícita e implícita que reaparece a lo largo de la obra borgesiana. Un cuento en el que ello es obvio es "Funes el memorioso", donde el personaje Funes cuenta con la capacidad de una memoria perfecta y absoluta, pero esa condición tan particular le resulta inútil a la hora de trascender su condición humana, puesto que sus recuerdos «no eran simples; cada imagen visual estaba ligada a sensaciones musculares, térmicas, etc. Podía reconstruir todos sus sueños, todos los entresueños. Dos o tres veces había reconstruido un día entero; no había dudado nunca, pero cada reconstrucción había requerido un día entero» (Obras completas I, 488). A diferencia del narrador de «El inmortal», Funes era capaz de reconstruir sistemática y sincrónicamente su pasado en la mente, pero la reconstrucción de tan sólo un día tomaba otro día. El recuerdo de un día, entonces, se convierte en un nuevo evento o contingencia para recordar, pero esta vez la reconstrucción del evento equivaldría a recordar un recuerdo dentro de otro recuerdo. Si agregamos días a la memoria, nos damos cuenta de que estamos hablando de valores infinitos dentro de los parámetros finitos de nuestra existencia. De hecho, el cuento reconoce ese dilema; el narrador señala que Funes pensó «que en la hora de la muerte no habría acabado aún de clasificar todos los recuerdos de la niñez» (489).

Vemos, entonces, que si fuese posible contar con un ser humano que además de ser inmortal (y así vivir todos los destinos de todos los hombres) tuviera una memoria perfecta con la capacidad de recordar, fuera del lenguaje, todo un pasado de manera sincrónica y no tan sólo diacrónica, nos enfrentamos con un nuevo problema: el de la infinita acumulación de memorias que existen dentro de otras memorias. Pero aun así, si fuese posible contar con un ser de tales características, éste todavía no podría definir su yo o identidad y, por supuesto, sería imposible para él también crear un vocabulario final que permitiese una definición del concepto de la identidad en sí, puesto que para ello no sólo ese individuo debería interrumpir la reconstrucción de sus días, sino que debería transferir esa reconstrucción al lenguaje que, como ya lo hemos discutido, es de carácter diacrónico.

Respecto a las limitaciones lingüísticas con relación a la memoria, recordemos que también una de las preocupaciones de Funes era la de poder mejorar el lenguaje, para que dejara de ser una aproximación a la hora de describir la realidad de sus recuerdos, y de hecho considera para ello diversos sistemas epistémicos que le permitieran clasificar esos recuerdos fehacientemente. Borges, jugando con la idea del Aleph, o conjunto absoluto que contiene todos los conjuntos y que luego aparecería más concretamente en su obra, subraya en el cuento, en palabras de Funes, que «los dos proyectos que he indicado (un vocabulario infinito para la serie natural de los números, un inútil catálogo mental de to- 
das las imágenes del recuerdo) son insensatos, pero revelan cierta balbuciente grandeza» (489-90). Son insensatos, puesto que por un lado no son aprehensibles, mientras que por otro lado, de serlos alcanzaríamos un absoluto y un absoluto es ese momento en el cual todo misterio se resuelve, toda paradoja deja de serlo, perdiendo su condición de tal. Pero ni bien ello ocurre, dejamos de pensar y todo evento, concepto o idea deja de ser interesante. Y sabemos que Funes «no era muy capaz de pensar. Pensar es olvidar diferencias, es generalizar, abstraer» (490). Una de las consecuencias de este lenguaje ideal en el que cada experiencia humana o cada objeto de la realidad recibe un signo lingüístico único, señala Philip Seargeant al estudiar «Funes el memorioso», reside en eliminar la idea de prototipos (394). De esa manera, cada experiencia humana sería diferente de todas las demás, y haría de cada ser un individuo único y, en cierto sentido, estas experiencias individuales estarían desligadas del lenguaje. Pero, a nuestro modo de ver, eso es precisamente lo que Borges trata de negar y lo que sugiere, como lo mencionamos antes, es que «Un hombre se confunde, gradualmente, con la forma de su destino; un hombre es, a la larga, sus circunstancias» (Obras completas I, 598); así todo ser humano, su yo, es producto de contingencias, pero el destino de un hombre es el destino de todos los demás hombres. Por otro lado, los experimentos lingüísticos de Funes «revelan cierta balbuciente grandeza», puesto que nos llevan a considerar la descripción de la realidad más allá de los límites finitos de nuestros sistemas epistémicos, y así Borges pone en duda la veracidad de absolutamente todo sistema formal de conocimiento, al mismo tiempo que, a través de la escritura ironista, es capaz de postular diferentes definiciones sin pretender ninguna de ellas constituirse como definitiva.

Pero como se subrayó al comienzo sobre «El inmortal», la estructura de su narración es caótica, haciendo que sea imposible determinar definitivamente quién es quién y proponiendo la existencia de un yo escurridizo. Relacionando esa idea con el tema de la memoria, este caos se debe, en gran medida, a que el narrador escribe sobre los hechos que le preocupan un año después de convertirse en un ser mortal y haciendo uso de las lenguas que ha heredado de sus precursores. Han pasado centenas de años y lo que él relata es, en verdad, una lectura de la realidad que le tocó vivir, es decir, es su traducción al papel de esa realidad ${ }^{19}$. Ahora bien, ¿es la traducción del narrador fidedigna a los hechos? El texto subraya que:

La historia que h[a] narrado parece irreal porque en ella se mezclan los sucesos de dos hombres distintos. En el primer capítulo, el jinete quiere saber el nombre del río que baña las murallas de Tebas; Flaminio Rufo, que antes ha dado a la ciudad el epíteto de Hekatómpylos, dice que el río es el Egipto; ninguna de esas locuciones es adecuada a él, sino a Homero [...] (543).

El narrador, entonces, comienza a darse cuenta de su propio plagio. Los hechos que realmente pertenecen a su existencia no son, ni en lo más mínimo, claros, en parte porque él mismo es el producto de la lengua y el producto de sus precursores; su condición de ser inmortal, ahora que es otra vez mortal, no lo ha puesto en ventaja respecto al resto de los hombres.

Si las experiencias de dos personas, o más, se hallan entremezcladas en una, la narración mediante la cual se explican tales experiencias tendrá las mismas características.

19 Recordemos que el corpus del cuento es, en realidad, una supuesta versión del inglés al castellano, de un documento hallado en la traducción de Pope de La Ilíada. 
De allí que, según el personaje del cuento, algunos hayan juzgado la narración de los hechos de apócrifa. El traductor ficticio del manuscrito prevé esos juicios y decide escribir falazmente una anacrónica posdata con fecha de 1950, un año después de la edición del cuento (pero que aparece en la versión original del 49), en la que nos dice, refiriéndose a un supuesto doctor Nahum Cordovero ${ }^{20}$ : «Infiere de esas intrusiones, o hurtos, que todo el documento es apócrifo. A mi entender, la conclusión es inadmisible. Cuando se acerca el fin, escribió Cartaphilus, ya no quedan imágenes del recuerdo; sólo quedan palabras. Palabras, palabras desplazadas y mutiladas, palabras de otros, fue la pobre limosna que le dejaron las horas y los siglos» (544).

Toda escritura, entonces, literaria o no, sería sólo un conjunto de palabras que en realidad pertenece a otros, que heredamos de otros, pero que en el proceso hereditario se convierten a la vez en nuestras. Absolutamente todo sería apócrifo si nos ajustáramos al juicio del doctor Cordovero. Pero esas inferencias, creemos, no se limitan a comentar sobre la escritura, sino también sobre todas las disciplinas del conocimiento y sobre la condición humana en sí y lo que ella constituye: es el producto de las palabras, es el producto del lenguaje y de la memoria o, mejor dicho, de la falibilidad de la misma.

Podemos notar, entonces, cómo el narrador de «El inmortal», a medida que hila su relato, crea una analogía de su propia vida en relación a la de aquellos que le precedieron y los imagina en un mundo en el que todos (incluso él) interactúan fuera del tiempo, sin tener en cuenta una cronología finita sino más bien transfinita. Pero el comentario borgesiano respecto a la condición del yo no acaba allí, sino que obliga al lector a imaginar, una y otra vez, el papel de un individuo que mitológicamente existe como ser inmortal; quizá sea ésta la analogía de las analogías. Nos referimos al personaje bíblico cuyo nombre es José, o Joseph. Pensemos en el personaje del cuento Joseph Cartaphilus y tratemos de comprender las razones (no inocentes) de su inclusión en el mismo. Gaston Paris, en su libro titulado Légendes du moyen âge ${ }^{21}$, estudia el origen de ciertas leyendas medievales que se propagaron por Europa y en las cuales se hacía alusión al judío errante, es decir a aquel judío que presenció la crucifixión de Jesucristo, que lo golpeó en la nuca y que fue condenado a errar por sobre la faz de la tierra hasta la segunda venida del Nazareno. Entre esas leyendas existe una que aparece en forma escrita por primera vez en 1228, por mano de un monje de Saint-Alban, Mathieu Paris, y en la que el José bíblico lleva por nombre Cartaphilus. Más tarde, en 1668, otra historia escrita por el alemán Droscher se publica en Venecia, y José recibe en ella el nombre por el cual lo conocemos hoy en día, Joseph (Paris, 149-221). Según esas y otras leyendas, el mismo Joseph apareció durante un sermón en una iglesia de Hamburgo, bajo el nombre de Ahasuerus, y hablaba perfectamente el alemán; más tarde se lo ve en Holanda, pero esta vez hablando un impecable castellano, luego pasó a Francia, hablando el francés, y la última vez de la que se oyó hablar de él fue en 1774, cuando se dice haberlo visto en Bruselas, donde narra su historia a la alta burguesía y cambia su nombre a Isaac Laquedem ${ }^{22}$. Borges juega con las ideas

20 Cabe preguntarse si Borges habría pensado en el místico Moshe Cordovero (1522-1570), que fue el primero en sistematizar la filosofía judía dando lugar a la cábala. Y los cabalistas, aparentemente, fueros los que más claro tenían el concepto del infinito, utilizando también el Aleph para simbolizar este infinito que para ellos es Dios (Aczel, 36).

21 Sería difícil asegurar que Borges hubiera leído este libro, pero no nos cabe duda de que sí había leído las leyendas medievales a las que el libro de Paris se refiere.

22 Recordemos, como lo señala la introducción del supuesto traductor, que Cartaphilus «se manejaba con fluidez e ignorancia en diversas lenguas; en muy pocos minutos pasó del francés al inglés y del inglés a una 
que él y sus lectores han heredado de otros y, usando la analogía, subraya las semejanzas y diferencias que nos caracterizan a todos. De esa manera, el cuento muestra cómo el escritor y el lector pueden valerse de la tradición escrita (u oral) heredada para señalar que todo intento de ir más allá del lenguaje con el fin de explicar la condición humana es fútil, pero, sin embargo, si somos conscientes de esas limitaciones y las aceptamos, nos abren la puerta a la imaginación y nos permiten ver la realidad más allá de los límites finitos que las distintas disciplinas humanas nos han impuesto ${ }^{23}$.

En «El inmortal» también vemos que de la misma manera que Joseph, por haber existido desde la crucifixión de Jesucristo y por continuar existiendo, aunque mitológicamente, hoy en día, puede verse como el arquetipo de todos los seres, Homero, podríamos decir, es el del escritor universal. Ronald Christ señala que si tenemos en cuenta la idea de un escritor universal, o de una figura literaria universal, podemos ver que la unión metafórica de todos los personajes en el cuento lleva al lector a explorar las conexiones literarias que unen a todos los aparentemente diferentes personajes del mismo (207). Probablemente, como se sugirió al comienzo, la tendencia del lector no será sólo la de enfocarse en las conexiones literarias, sino también en los enigmáticos personajes de la obra y, a través de falsos elementos identificadores provistos por el autor, tratar de conectar al jinete sangriento con la flecha cretense y el dolor punzante en el pecho que sufre el narrador, a fin de establecer una identidad y llegar, quizá, a la conclusión de que esa figura universal (artista y humano) es Homero. Pero creemos que lo que Borges quiere, en realidad, no es necesariamente que el lector identifique una identidad en particular, sino que sea capaz de descifrar la analogía. Octavio Paz nos dice que el poeta es:

Un traductor, un descifrador. Cada poema es una lectura de la realidad; esa lectura es una traducción; una traducción es una escritura: un volver a cifrar la realidad que se descifra. La poética de la analogía consiste en concebir la creación literaria como una traducción; esa traducción es múltiple y nos enfrenta a esta paradoja: la pluralidad de autores [...] La analogía es la metáfora en la que la alteridad se sueña unidad y la diferencia se proyecta ilusoriamente como identidad (109-10).

Si Paz no se equivoca, entonces la idea borgesiana de usar una figura universal como analogía que se convierte en metáfora hace que el lector cree a la vez una analogía entre la creación literaria y la creación de su ser.

Borges, como ya lo sugerimos, juega fundamentalmente con ciertas ideas que sólo pueden ser consideradas cuando las contemplamos más allá de la finitud; lenguaje y memoria son dos de ellas. El narrador, al hallar el río que devuelve la mortalidad, dice: «Todo me fue dilucidado aquel día» (540). Y nos dice que lo que realmente le es revelado es la ironía de que "Ser inmortal es baladí; menos el hombre, todas las criaturas lo son, pues ignoran la muerte» (540). Y eso lleva al lector a darse cuenta de que cuando consideramos lo inevitable, y aun lo inexplicable, es decir la muerte, nos hallamos frente a otra incertidumbre: no podemos ir más allá de la misma en cuanto al conocimiento, ni tampoco comprender quiénes somos en realidad, puesto que somos productos de múltiples contingencias. Por otro lado, como el artista, lo que sí podemos hacer es apropiarnos de esas contingencias que enfrentamos a lo largo de nuestras vidas y mediante la ima-

conjunción enigmática de español de Salónica y de portugués de Macao» (533).

23 Rorty, refiriéndose al tema, señala: «We are doomed to spend our conscious lives trying to escape from contingency rather than, like the strong poet, acknowledging and appropriating contingency» (28). 
ginación trascender las finitudes epistémicas que nos atrapan, y así llegar a comprender ciertos aspectos de la realidad bajo una lente diferente.

Tal como es el caso del narrador del cuento, nuestra historia no es la historia de una figura fuera de la historia que contempla y entiende el universo desde una posición privilegiada. Todo lo contrario, nuestra relación de dependencia para con la memoria, el lenguaje y nuestra habilidad de hacer nuestras las contingencias que se presentan en nuestras vidas es lo que nos ayuda a ir más allá de nuestros precursores mediante la redescripción y reinterpretación, pero sólo para reconocer la influencia que ellos han tenido en nosotros. Por lo tanto, la conclusión a la que llega el narrador es realmente plausible: el documento apócrifo que todos nosotros escribimos es, necesariamente, ficticio. Pero además de ser ficticio es también ilimitado, infinito.

Dijimos al comienzo que los relatos contenidos en El Aleph, de una u otra manera tratan sobre un absoluto, o más bien sobre la imposibilidad de aprehender un absoluto y de poder establecer un vocabulario final que defina un absoluto en particular. Pero a la vez, esos relatos, a pesar de que sus premisas son de por sí sabidas y aparentemente inútiles, en el sentido de que tratan temas que no tienen resolución, no por ello dejan de tener vigencia hoy en día. Borges, entre otras cosas, como Cantor y muchos otros, trata de que sus lectores seamos capaces de vislumbrar la realidad más allá de la finitud establecida por las disciplinas que nos rigen y que lleguemos a darnos cuenta de nuestra insignificancia frente al «inconcebible universo» (Obras completas I, 626), forzándonos a cuestionar nuestras propias ideas y las de los demás, permitiéndonos así llegar al entendimiento de que ningún sistema epistémico es mejor que otro y que cada uno de ellos es incapaz de comunicar objetivamente ningún tipo de conocimiento. Si repasamos otro de los cuentos contenidos en El Aleph, «La casa de Asterión», notamos una vez más tales aserciones, por ejemplo cuanto Asterión reflexiona sobre el número de puertas que su vivienda tiene y decide que ese número es infinito. Irónicamente, el autor comenta en una nota al pie de página que «el original dice catorce, pero sobran motivos para inferir que, en boca de Asterión, ese adjetivo numeral vale por infinitos» (Obras completas I, 669). Podría haber dicho catorce como cualquier otro número, puesto que en realidad ese número es una abstracción epistémica; creer que el lenguaje matemático (o cualquier otro) puede ser capaz de representar coherentemente algo es propiedad tan sólo de una aritmética finita y, de cierta manera, obtusa. Asterión reflexiona más luego: «no me interesa lo que un hombre pueda transmitir a otros hombres; como el filósofo, pienso que nada es comunicable por el arte de la escritura [...] jamás he retenido la diferencia entre una letra y otra» (569).

Esa idea también está presente en «El inmortal». El supuesto narrador poco a poco comienza a darse cuenta de que no puede trascender las limitaciones impuestas por el lenguaje y tratar de hallar un lenguaje absoluto, llegando a la conclusión de que quizá no sólo sea incapaz de describir la realidad, sino que incluso es posible que toda descripción sea una ensoñación: «Ignoro si todos los ejemplos que he enumerado son literales; sé que durante muchos años infestaron mis pesadillas; no puedo ya saber si tal o cual rasgo es una transcripción de la realidad o de las formas que destinaron mis noches» (538). Y por tal razón decide no continuar la tarea de describir la Ciudad de los Inmortales: «no quiero describirla; un caos de palabras heterogéneas, un cuerpo de tigre o de toro, en el que pulularan monstruosamente, conjugados y odiándose, dientes, órganos y cabezas, pueden (tal vez) ser imágenes aproximativas» (538). La descripción a través del lenguaje, por lo tanto, tan sólo puede llegar a ser una aproximación de lo que se intenta describir. 
Pero volviendo a «El Aleph», podemos resumir las ideas aquí presentadas a través de la reflexión del narrador después de haber visto el Aleph:

el problema central es irresoluble: la enumeración siquiera parcial, de un conjunto infinito. En ese instante gigantesco, he visto millones de actos deleitables o atroces; ninguno me asombró como el hecho de que todos ocuparan el mismo punto sin superposición y sin transparencia. Lo que vieron mis ojos fue simultáneo; lo que transcribiré, sucesivo, porque el lenguaje lo es. Algo, sin embargo, recogeré (Obras completas I, 625).

Dos cosas esenciales podemos extrapolar de la cita anterior. En primer lugar notamos que Borges alude al lenguaje matemático y a la imposibilidad de enumerar un conjunto infinito, puesto que la aritmética que nos permite establecer que algo es verdadero no es finita y se resiste a la serialización del infinito. En segundo lugar, vemos que esa alusión al lenguaje matemático se ve proyectada a todo lenguaje, puesto que ya sea que hablemos de un conjunto infinito o de uno finito, los elementos individuales de un conjunto en sí están compuestos de un número infinito de otros elementos y que todos ellos ocupan el mismo punto de manera simultánea. Si hablamos, por ejemplo, del yo individual de una sola persona en un instante cualquiera, en ese instante se conjugan un número infinito de elementos de manera simultánea cuya descripción también resiste la serialización, puesto que el lenguaje es sucesivo (diacrónico) y no simultáneo (sincrónico). Pero sabemos también que para Borges ésa no es razón para dejar de lado la descripción, «Algo, sin embargo, recoger[á]», puesto que es precisamente la constante redescripción la que nos permite resolver ciertas aporías, a la vez que mediante la misma se revelan otras nuevas.

Esta característica ironista de la escritura borgesiana es la que, en realidad, permite la continuación del diálogo intelectual a través de las distintas disciplinas del conocimiento. Tal como Borges señala en "La esfera de Pascal», "Quizá la historia universal es la historia de la diversa entonación de algunas metáforas» (Obras completas II, 14,16). Así, «El inmortal» se convierte en otra entonación (o renovación, o redescripción) de la metáfora que encierra los multifacéticos e infinitos elementos que componen un yo. «El inmortal», dentro de nuestra visión finita del universo, nos presenta una historia que puede sin dificultad alguna ser rotulada de fantástica, de metafísica y apócrifa, pero como toda metáfora, su propósito es el de llevarnos a considerar un concepto infinito a través de un lenguaje transfinito. La metáfora, recordemos, resume en sí las infinitas explicaciones que de ella puedan postularse, pero ninguna explicación individual es capaz de establecerse como vocabulario final de esa metáfora. El yo es una metáfora de un infinito número de cosas; «El inmortal» es una de las diversas entonaciones de esa metáfora. Este ensayo, siguiendo el mismo hilo, es tan sólo una posible explicación de la compleja metáfora que es en sí «El inmortal».

\section{REFERENCIAS}

Aczel, Amir D. The Mystery of the Aleph: Mathematics, the Kabbalah, and the Search for Infinity. New York: Washington Square Press, 2000. Medio impreso.

Bloom, Harold. The Anxiety of Influence: A Theory of Poetry. New York: Oxford U.P., 1997. Medio impreso. 
Borges, Jorge Luis. Obras completas, 4 vols. Barcelona: Emecé, 1989. Medio impreso.

___. Inquisiciones. Barcelona: Seix Barral, 1994. Medio impreso.

-_- Textos recobrados (1919-1929). Buenos Aires: Emecé, 1997. Medio impreso.

Christ, Ronald. The Narrow Act: Borges's Art of Illusion. New York: Lumen Books, 1995. Medio impreso.

Davidson, Donald. «What Metaphors Mean». Inquiries into Truth and Interpretation. New York: Oxford U.P., 2001. Medio impreso.

Ferrari, Osvaldo. «El culto de los libros». En Diálogo II: Jorge Luis Borges. Buenos Aires: Editorial Sudamericana, 1986. Medio impreso.

Hernández, Juan Antonio. "Biografía del infinito: La noción de transfinitud en Georg Cantor y su presencia en la prosa de Jorge Luis Borges». Signos Literarios y Lingüísticos II:2 (diciembre 2000), 131-139. Medio impreso.

Kasner, E. y J. Newman. Matemáticas e imaginación. México: Compañía Editorial Continental, 1978. Medio impreso.

Lyotard, Jean-François. The Postmodern Condition: A Report on Knowledge. Traducción de Geoff Bennington y Brain Massumi. Minneapolis: University of Minnesota P., 1984. Medio impreso.

Mansbach, Abraham. «El inmoral» de Borges a través de la concepción Heideggeriana de la muerte y de la individualidad». Revista Hispánica Moderna L: I (1997). 110-15. Medio impreso.

Mualem, Shlomy. "What Can Be Shown Cannot Be Said: Wittgenstein's Doctrine of Showing and Borges' The Aleph». Variaciones Borges 13 (2002). 41-56. Medio impreso.

Paris, Gaston. Légendes du moyen âge, 2m éd. París: Librairie Hachette et Cie., 1904. Medio impreso.

Paz, Octavio. Los hijos del limo: del romanticismo a la vanguardia. Barcelona: Seix Barral, 1989. Medio impreso.

Riva, Reynaldo. «Mélanges: Asedios a «El inmortal». Revue Romane 40:2 (2005). 315328. Medio impreso.

Rorty, Richard. Contingency, Irony, and Solidarity. New York: Cambridge U.P., 1989. Medio impreso.

Stewart, Jon. "Borges on Language and Translation». Philosophy and Literature 19:2 (1995). 320-329. Medio impreso.

Seargeant, Philip. "Philosophies of Language in the Fictions of Jorge Luis Borges». Philosophy and Literature, 33:2 (2009). 386-401. Medio impreso.

Recepción: 1 de agosto de 2010 Aceptación: 3 de enero de 2011 